\title{
Barriers to and facilitators of ultra-processed food consumption: perceptions of Brazilian adults
}

\author{
Luara Bellinghausen Almeida ${ }^{1}$, Fernanda Baeza Scagliusi ${ }^{2,3}$, Ana Clara Duran ${ }^{3}$ and \\ Patricia Constante Jaime ${ }^{2,3, *}$ \\ 'Public Health Nutrition Postgraduate Program, School of Public Health, University of São Paulo, São Paulo, SP, \\ Brazil: ${ }^{2}$ Department of Nutrition, School of Public Health, University of São Paulo, Av. Dr Arnaldo 715, São Paulo, \\ SP, Brazil, 01246-904: ${ }^{3}$ Centre for Epidemiological Studies in Health and Nutrition, University of São Paulo, \\ São Paulo, SP, Brazil
}

Submitted 25 October 2016: Final revision received 15 May 2017: Accepted 12 June 2017: First published online 25 July 2017

\begin{abstract}
Objective: To explore how individuals perceive the availability of ultra-processed foods in their neighbourhoods and the barriers to and facilitators of consumption of such foods.

Design: A qualitative design was chosen. In-depth, face-to-face semi-structured interviews were conducted and a content analysis was performed.

Setting: São Paulo, Brazil.

Subjects: A purposeful sample of adults ( $n$ 48), stratified by sex and age group (20-39 years and 40-59 years).

Results: All participants perceived their neighbourhoods as favourable regarding the availability of ultra-processed foods. Three barriers were identified: health concerns, not appreciating the taste of these foods and not being used to eating them. Five facilitators, however, were identified: appreciating the taste of these foods, their children's preference, convenience, addiction and cost.

Conclusions: Participants perceived their neighbourhoods as favourable to the consumption of ultra-processed foods and reported more facilitators than barriers to their consumption. Reported barriers point to the need to include measures promoting a healthy food system and traditional eating practices. The facilitators reinforce the idea that these foods are habit-forming and that regulatory measures to offset the exposure to ultra-processed foods are necessary.
\end{abstract}

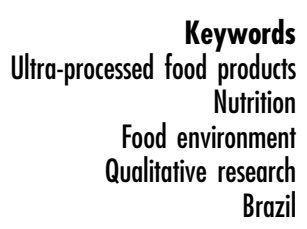

In recent years a new healthy eating paradigm that considers the extent and purpose of industrial processes applied to food has emerged ${ }^{(1)}$. The concept of ultraprocessed foods has been applied in the study of population eating patterns and their relationship to health and wellness ${ }^{(2-5)}$. Ultra-processed foods are formulations made by the food industry, using substances extracted from natural or unprocessed foods or obtained from the further processing of constituents of foods or through chemical synthesis. The main purpose of industrial ultraprocessing is to create products that are durable, accessible, convenient and highly palatable, ready to drink or ready to eat ${ }^{(6)}$.

Ultra-processed foods have higher energy density, higher free sugar content and lower micronutrient and fibre contents than natural or minimally processed foods. Thus, the consumption of these foods impacts the nutritional profile of the diet ${ }^{(7-9)}$. They have also been associated with obesity ${ }^{(10,11)}$.
Recently, the proportion of dietary energy in ultraprocessed products was recommended as an indicator of the quality of diets by the INFORMAS (International Network for Food and Obesity/non-communicable Diseases Research, Monitoring and Action Support) initiative $^{(12)}$. The utility of the concept of ultra-processed foods has been recognized not only for nutritional epidemiology studies, but also for the development of public health policies. In 2014, the Ministry of Health of Brazil updated the national dietary guidelines for the Brazilian population and among its recommendations there is the following golden rule: 'Always prefer natural or minimally processed foods and freshly made dishes and meals to ultra-processed products ${ }^{(1,13)}$. Two years later, the Pan American Health Organization presented a Nutrient Profile Model as a tool to classify processed and ultra-processed food and drink products that contain excessive amounts of critical nutrients such as sugars, salt, total fat, saturated fat and trans-fatty acids. This model is 
intended to help in the design and implementation of various strategies related to the prevention and control of obesity $^{(14)}$.

Food choices, including ultra-processed foods, are inserted in the actions that form part of one's eating habits and are determined by a number of other factors that go through cognitive, emotional, behavioural, social and environmental elements ${ }^{(15)}$. Moving beyond the recommendation about what people should eat, the Brazilian Guidelines clearly recognize key obstacles that can prevent people from adopting such a recommendation; for instance, access to information, food availability, cost, cooking skills, time and food marketing. The majority of these obstacles are directly related to the food environment ${ }^{(1,13)}$. Taking into account that common attributes of ultra-processed foods are hyper-palatability, sophisticated and attractive packaging, multi-media and other aggressive marketing strategies ${ }^{(6)}$ which have a broad potential to influence food choices, the better understanding of the factors that guide the choice of these foods can support the formulation of nutrition interventions. Some previous studies have explored the drivers of consumption and values of what they named 'convenience food',(16,17). Nevertheless, there is a lack of qualitative research that can deeply investigate factors promoting or discouraging the consumption of ultra-processed foods. Thus, the present study qualitatively explored, in a Brazilian sample: (i) how individuals perceive the availability of ultra-processed foods in their neighbourhoods; and (ii) the barriers to and facilitators of consumption of such foods.

\section{Methods}

\section{Study design and sample}

The present paper is part of the Obesogenic Environment Study in São Paulo, Brazil (ESAO-SP), a multi-method research project which examined the relationship between aspects of the local food environment and food access and consumption in São Paulo. Located in the Southeast region of Brazil and with a population of over 11 million, the city of São Paulo is the largest city in the country and one of the most populous urban agglomerations in the world. Despite being the richest city in Brazil, São Paulo has an unequal distribution of wealth ${ }^{(18)}$. ESAO-SP used a crosssectional design and drew upon three data sources from São Paulo city: (i) a local food environment audit of thirteen districts in the city that ensured representation of São Paulo's socio-economic and food environment diversity; (ii) a survey to collect individual-level characteristics; and (iii) a purposeful sample of forty-eight adults stratified by sex (male and female) and age (20-39 years and 40-59 years). More details on the methodology of ESAO-SP can be obtained in previous publications ${ }^{(19,20)}$. Briefly, we used the Human Development Index to classify each district according to the socio-economic level. Within each tertile of the Human Development Index, districts were classified into low or high food environment density (per 10000 district residents). The food environment classification was based on whether the districts were below or above the median on all of three selected food environment indicators: (i) local grocery stores and supermarkets; (ii) specialized fruit and vegetable stores/ markets and open-air food markets; and (iii) fast-food restaurants. Then two districts from each of the six combined strata of Human Development Index and food density were randomly selected. An extra district, which was adjacent to one of the selected districts within the highest tertile of Human Development Index, was selected to offset potential data loss. No data were lost but the thirteenth district was retained in the analyses to maximize sample size. Eight census tracts were randomly selected in each district. Out of the 104 tracts initially selected, eighteen were excluded, yielding eighty-six eligible tracts. The excluded tracts did not differ from the totality of the selected tracts in terms of mean income and education levels. Of the remaining eighty-six tracts, four were randomly sampled in each of the thirteen selected districts, resulting in a final count of fifty-two census tracts ${ }^{(19)}$. Individual-level characteristics were gathered from an ageand sex-stratified sample of 2000 adults who lived or worked in those same districts where local food environment-level data were obtained ${ }^{(20)}$.

The qualitative sample was purposefully selected from our survey considering gender, age, and socio-economic and food environment diversity. Individuals who agreed to share their contact information during the survey were identified to be included in the qualitative study. From each socio-economic and food environment stratum, six males and six females from each age group (18-39 years, 40-59 years) were randomly selected to give us three times as many possibilities to achieve our goal of interviewing fifty-two individuals (four adults per district). They were contacted by telephone and forty-eight individuals who fit our selection criteria agreed to participate in the study. All participants $(n 48)$ received written information explaining the study and signed individual consent forms. Ethics approval was granted by the Human Research Ethics Committee of the University of São Paulo's School of Public Health.

\section{Data collection}

In-depth, face-to-face semi-structured interviews were conducted by a trained registered dietitian and an undergraduate student between March and August 2012.

To elaborate the interview guide, we started with two broad questions: (i) how do individuals from each neighbourhood perceive the availability of foods and of restaurants and retail food stores, and how does the presence of these restaurants/stores affect their eating practices; and (ii) where do individuals shop for food, prepare routines of food shopping, preparation and 
consumption, and how do they relate with food intake, especially of fruits, vegetables and ultra-processed foods? After fully discussing such questions, the authors ended up with an interview guide with sixteen open questions. They were designed to elicit participants' perceptions regarding: (i) practices and difficulties with food shopping, preparation and consumption; and (ii) how the presence of retail food stores in their neighbourhoods (characteristics, presence of certain food) are associated with their eating practices.

The pre-test was conducted with four participants (two men and two women) with different levels of education; and helped us to improve the interview guide. The interviews were audio-taped and then fully transcribed. Mean duration of the interviews was $35 \mathrm{~min}$, ranging from 12 to $47 \mathrm{~min}$.

\section{Data analysis}

A content analysis was performed to analyse the interviews' transcripts. A trained researcher read the transcripts several times to achieve an immersion into the data. Given the objective of the present paper, excerpts regarding ultra-processed foods ( $n$ 113) were extracted from the text and further analysed using the qualitative data analysis software NVivo 10. The approach given to text analysis included a deductive and an inductive design. It started with a more theory-driven investigation, but also allowed new categorizations to emerge from the findings. We conducted a classical and an exploratory content analysis. Bernard and Ryan ${ }^{(21)}$ defined content analysis as 'a set of methods for systematically coding and analyzing qualitative data (...) used to explore explicit and covert meanings in text'. Classical content analysis is deductive and uses codes derived from theory, while an exploratory content

Table 1 Sociodemographic data and food intake of the participants who lived or worked/studied in the investigated neighbourhoods of the city of São Paulo. ESAO-SP study, São Paulo, Brazil, 2012

\begin{tabular}{|c|c|c|}
\hline & \multicolumn{2}{|c|}{ Total $(n$ 48) } \\
\hline & $n$ & $\%$ \\
\hline \multicolumn{3}{|l|}{ Sex } \\
\hline Men & 26 & $54 \cdot 2$ \\
\hline Women & 22 & $45 \cdot 8$ \\
\hline \multicolumn{3}{|l|}{ Age } \\
\hline $20-39$ years & 26 & $54 \cdot 2$ \\
\hline $40-59$ years & 22 & $45 \cdot 8$ \\
\hline \multicolumn{3}{|l|}{ Education (level of schooling) } \\
\hline Less than high school & 9 & $18 \cdot 8$ \\
\hline High school & 26 & $54 \cdot 2$ \\
\hline College & 13 & $27 \cdot 0$ \\
\hline Live in the neighbourhood & 30 & 62.5 \\
\hline Study/work in the neighbourhood & 18 & 37.5 \\
\hline Buy foods in the neighbourhood & 34 & $70 \cdot 8$ \\
\hline Regular intake of sugar-sweetened beverages ${ }^{*}$ & 32 & $66 \cdot 7$ \\
\hline Regular intake of chips* & 18 & 37.5 \\
\hline Regular intake of cookies* & 24 & $50 \cdot 0$ \\
\hline Regular intake of fast-food ${ }^{*}$ & 29 & $60 \cdot 4$ \\
\hline
\end{tabular}

${ }^{*}$ Regular intake $=$ eating $\geq 5$ times/week. analysis is more inductive and uses codes derived from data. Initially, the classical content analysis included 'perceptions regarding the availability of ultra-processed foods in the participants' neighbourhoods' as an a priori category, and with 'favourable' or 'unfavourable' as the possible sub-categories. Further, for the categories 'barriers to and facilitators of the consumption of ultraprocessed foods', inductive sub-categories were identified using the 'cutting and sorting' approach. Bernard and Ryan $^{(21)}$ described it as a process that 'involves identifying quotes or expressions that seem important - these are called exemplars -, and then arranging the quotes/ expressions into piles of things that go together'. We started by manually taking notes. Second, using NVivo, we attached the codes and retrieved the sentences with the same sub-categories. Therefore, the sub-categories arose from the most relevant aspects of the data, using an inductive $\operatorname{approach}^{(21)}$. We present the number of excerpts classified in each category or sub-category and the quotes that best exemplify each category. The number of quotes in each sub-category was compared among men and women using the $\chi^{2}$ test and Yates correction on the website Quantpsy.

\section{Results}

Table 1 shows the characteristics of the participants. A total of forty-eight participants were interviewed, of whom $54.2 \%$ graduated from high school, $62.5 \%$ lived in the studied neighbourhoods and $70 \cdot 8 \%$ bought food in their neighbourhood, mainly because of the high cost or the lack of quality of the food establishments. At least half of the sample reported regular consumption of ultraprocessed foods (sugar-sweetened beverages, cookies and/or salty snacks) five times or more per week.

We extracted a total of 115 quotes (Table 2). The individuals were classified according to their perceptions regarding their food environment. While most of the participants perceived their neighbourhood environments as favourable to the availability of ultra-processed foods, two could not classify their environment as favourable or unfavourable (Table 2). Illustrative quotes of the participants who classified their environment as favourable are presented below:

'There are a lot of fast-food restaurants here. Yes, you can find chips and sandwiches. Across the street, at the bakery. But the supermarket also has all these things. There are even frozen sandwiches, which you can warm up in the microwave.' (Woman)

'You can find chips, cookies and soda virtually everywhere; at small markets, bars, bakeries. There are a lot of soda, bread and lunch meats, they sell a lot at the bakery and at the bar.' (Woman) 
Table 2 Perceptions on the availability of ultra-processed foods in the neighbourhood and barriers to and facilitators of consumption of such foods. ESAO-SP study, São Paulo, Brazil, 2012

\begin{tabular}{lrr}
\hline & Total $(n$ 48) \\
\cline { 2 - 3 } & No. of participants interviewed & $\%$ \\
\hline Perceived that ultra-processed foods were available in the neighbourhood & 48 & $100 \cdot 0$ \\
The neighbourhood favoured the availability & $95 \cdot 8$ \\
The neighbourhood did not favour the availability & 0 & $0 \cdot 0$ \\
The neighbourhood is neither favourable nor unfavourable & 2 & $4 \cdot 2$ \\
& No. of quotes in each category \\
or sub-category & $\%$ \\
\hline Factors related to the consumption of ultra-processed foods & 67 & $100 \cdot 0$ \\
Barriers to the consumption of ultra-processed foods & 30 & $44 \cdot 8$ \\
Health concerns & 20 & 29.9 \\
They disliked the taste of these food & 8 & 11.9 \\
Not used to eating these foods & 2 & 3.0 \\
Facilitators of the consumption of ultra-processed foods & 37 & $55 \cdot 2$ \\
They liked how these foods taste & 14 & 20.9 \\
Their children preferred to eat these foods & 8 & 11.9 \\
Convenience and readily available & 8 & 11.9 \\
Addiction & 4 & 6.0 \\
Cost & 3 & 4.5 \\
\hline
\end{tabular}

Table 3 Quotes that best exemplify the category 'barriers to the consumption of ultra-processed foods' and sub-categories

\begin{tabular}{|c|c|c|}
\hline \multicolumn{3}{|c|}{ Barriers to the consumption of ultra-processed foods } \\
\hline Health concerns & Disliking how these foods taste & Not used to eating these foods \\
\hline $\begin{array}{l}\text { 'I can’t eat chips, microwave popcorn, soda, } \\
\text { because I have high blood pressure. I avoid } \\
\text { them'. (Man) }\end{array}$ & $\begin{array}{l}\text { 'Soda, cookies, chips, sandwiches, I don't } \\
\text { like them. I can go without these, } \\
\text { especially soda. No, I don't even feel like } \\
\text { drinking it.' (Man) }\end{array}$ & $\begin{array}{l}\text { 'I don't eat ultra-processed foods. I don't like } \\
\text { cookies or chips. I don't like them because } \\
\text { I grew up at a farm and my grandmother } \\
\text { always guided us, she was a very wise. } \\
\text { Food was healthy and natural, no soda or } \\
\text { chips. She used to make bread, baked } \\
\text { goods ... Hence, I would almost never eat } \\
\text { industrialized food.' (Woman) }\end{array}$ \\
\hline $\begin{array}{l}\text { 'Since in my house everybody is somewhat } \\
\text { obese, I avoid candies and soda. I don't } \\
\text { buy them.' (Woman) }\end{array}$ & $\begin{array}{l}\text { 'I don’t like snacks or chips. Not even at } \\
\text { birthday parties. My stepmother just throw } \\
\text { me a party, but even then I didn't eat them.' } \\
\text { (Man) }\end{array}$ & $\begin{array}{l}\text { 'I don't like Coke }{ }^{\circledR} \text {, I don't like soda during the } \\
\text { meals. I am not used to drinking soda } \\
\text { because I did not drink as a child. It all } \\
\text { comes from your childhood. I never desired } \\
\text { to have soda.' (Woman) }\end{array}$ \\
\hline \multicolumn{3}{|l|}{$\begin{array}{l}\text { 'I don't eat [ultra-processed foods], and this is } \\
\text { why I am so healthful.' (Woman) }\end{array}$} \\
\hline $\begin{array}{l}\text { 'I ate cookies and sweets for many years. } \\
\text { Now, I eat less. I am not drinking as much } \\
\text { soda or eating fried foods, and I noticed } \\
\text { that my life got better, I started to have } \\
\text { better self-esteem.' (Woman) }\end{array}$ & & \\
\hline
\end{tabular}

More facilitators were perceived than barriers $(55.2$ and $44.8 \%$ of the sixty-seven quotes identified, respectively). We identified three barriers to the consumption of ultraprocessed foods: (i) health concerns; (ii) the fact that some participants reported that they did not like to eat these foods; and (iii) not being used to eating them. The frequency of these quotes is presented in Table 2 and some of the quotes that best exemplify such barriers are presented in Table 3. No differences in the frequency of quotes were observed between men and women $(P=0.69)$.

Health concerns were the most cited barrier (Table 2). Several participants suggested that ultra-processed foods were 'unhealthy' although they could not explain why these foods were not healthy. Some, however, could link the consumption of ultra-processed foods with non-communicable diseases, such as overweight and hypertension. As result, these participants said they avoid buying or eating these foods. Finally, a few participants mentioned the association of ultra-processed foods with well-being, health and good self-esteem (Table 3). Disliking how ultra-processed foods taste was the second most cited barrier. Four participants reported they were not used to eating ultra-processed foods because they did eat these foods growing up (Tables 2 and 3).

Five facilitators of the consumption of ultra-processed foods were identified: (i) liking to eat these foods; (ii) their children liked to eat these foods; (iii) convenience; 
(iv) addiction; and (v) cost (Table 2). Participants clearly stated how they enjoyed the taste of ultra-processed foods and how that was an important motivation for consumption (Table 4). The convenience of ultra-processed foods was also repeatedly reported. Participants reported eating them at home, at work, and when they were out having fun (Table 4). Finally, some participants referred to the consumption of ultra-processed foods as an addiction or chose to eat them because they were cheap (Table 4).

\section{Discussion}

We found that all participants perceived their environments as favourable to the availability of ultra-processed foods. They perceived these foods as readily available and reported that they were found in supermarkets, grocery stores, bars, cafeterias, restaurants and bakeries. Indeed, when analysing data from seventy-nine countries, Monteiro et al. found that these products are ubiquitous in developed countries and are increasingly being found in developing countries ${ }^{(22)}$. In fact, more facilitators than barriers to the consumption of ultra-processed foods were reported by the study participants, for whom personal liking or their children liking to eat these foods, convenience, addiction and cost facilitated consumption. This is worrisome, since high availability of ultra-processed foods affects cooking practices ${ }^{(23,24)}$ and is associated with overweight prevalence ${ }^{(25)}$.

The sample had a high proportion of individuals who reported to regularly consume sugared beverages, chips, cookies, and especially soda and fast food. Moreover, these individuals perceived more facilitators than barriers to the consumption of ultra-processed foods.

Food environment characteristics can shape the food pattern of the population; however, individuals do not necessarily associate their food consumption with the evident features of the environment ${ }^{(26-28)}$. Our findings showed that reported barriers to and facilitators of the consumption of ultra-processed foods were related to the characteristics of ultra-processed foods themselves or to their individual characteristics. These findings suggest that the influence of the food environment on dietary intake is not clear to individuals.

Ultra-processed foods are energy-dense, rich in saturated fat, trans fat, sugar and sodium, and poor in fibre and micronutrients. Besides that, they contain many additives, thus this kind of food can be dangerous to health ${ }^{(29-31)}$. Although our participants did not mention these specific characteristics, they identified health concerns as the main barrier to the consumption of ultra-processed foods. They associated the intake of these foods with several diseases and described subsequent actions, such as avoiding eating or buying them. Moreover, avoiding these foods was associated with better health, well-being and better selfesteem. Interestingly, a participant noted that although she knew cookies and soda were not good for her, she liked to eat them. Both taste and health are food values, namely factors considered important by individuals in constructing their food choices ${ }^{(32)}$. This participant's quote shows that attitude towards ultra-processed foods may be multidimensional, for example simultaneously positive and negative. This corroborates both the model of attitudinal ambivalence described by Conner and Armitage ${ }^{(33)}$ and the value negotiation process described by Sobal et al., where a certain value is prioritized and there are 'trade-offs' between opposing values ${ }^{(32)}$.

Taste is one of the primary factors determining food choice $^{(32)}$. In our study, participants referred liking the taste of a specific product' as the main facilitator of the consumption of ultra-processed foods (20.9\%); however, 'not liking the taste of a specific product' was the second most cited barrier (11.9\%). Ultra-processed foods are designed to be palatable because of their high content of sugar, fat and sodium. The use of flavourings and colourings can also make them very attractive ${ }^{(29,31)}$. Studies conducted in Brazil, Slovenia and Norway with adults identified a certain group that preferred simple, traditional and home-cooked foods and rejected fast foods and convenience foods ${ }^{(34)}$. In a survey with 439 Brazilian mothers, Sato et al. ${ }^{(35)}$ verified that $39 \cdot 9,25 \cdot 3$ and $37 \cdot 1 \%$ never or seldom bought ready-to-eat meals, used practical foods (such as noodles, ready tomato sauce, packaged soup and boxed cake mix) and liked to eat at fast-food restaurants, respectively. Future studies could focus on investigating the characteristics and drivers of individuals who do not like to eat ultra-processed foods, using more robust theoretical frameworks such the concepts of habitus as proposed by Bourdieu ${ }^{(36)}$ and the food choice trajectory as proposed by Sobal et al. ${ }^{(32)}$. In fact, the two participants who reported they were not used to eating ultra-processed foods as a barrier to their consumption also reported they did not like to eat them. They also mentioned that these foods were not part of their life.

An important facilitator of the consumption of ultraprocessed foods was the fact that participants' children liked to eat those foods and adults would buy these products as result of their children's food preferences. Exposure to advertising of ultra-processed foods may be driving such preferences among children and stricter regulatory measures should be implemented ${ }^{(37)}$. We found that the participants seemed to believe that children's preference for ultra-processed foods was a given, particularly because of the amount of sugar these foods contain. The idea that 'they like it' was widely accepted and generated several actions, such as the regular purchase of sugar-sweetened beverages and how children would regularly drink soda. Ochs et al. observed among North Americans that parents constructed generalizations about children's tastes: children only liked to eat dessert (which were mainly ultra-processed foods, such as ice 
Table 4 Quotes that best exemplify the category 'facilitators of the consumption of ultra-processed foods' and sub-categories

,

'I love cookies and soda. I have them 'They drink soda all the time, once a week, because I like it. It is not good for me, but I like it: (Woman)

'If I could I would have soda every day of the week. Lately I have been drinking the diet ones, like three days per week. I love it.' (Man)

'Soda, yes, every day. Chips, almost every day. And outside of my neighbourhood I eat sandwiches too. I used to eat snacks almost
every day for breakfast, outside, until my doctor told me to stop. I eat these foods because they taste good. Because I really like them.' (Woman)

kids like it, they don't eat (Woman) difficult.' (Woman)

Facilitators of the consumption of ultra-processed foods

Cost

II buy the types of juice and soda that 'Soda, cookies, chips, sandwiches, I eat them, very frequently. It is easier. Soda and cookies?! I keep
them at work. I just grab and eat I also keep chips at work. Thus I eat during the entire day while I am at work, as well as at home. Because is it easier, right?' (Man)

'If there is no soda, my children won't 'They [ultra-processed foods] are eat, they don't even care for food if very cheap things, and people I am used to, I don't eve like this, am used to, I don't even drink here don't have a lot of money, you
know, so if it is cheap, they sell a know, so if it is cheap, they sell
lot, everybody eats them, a lot.' water anymore, just soda. When go out, I don't even know how to (Woman) soda. I believe that I got addicted.' (Man)

'I eat it, because it is faster, I am too 'I have one glass of soda at lunch and lazy to make juice, because it because their father buys for them but cookies no, they eat them thre times per week. They eat chips another at dinner. It is an addiction. takes too long. That is the reality. But I have it, it is necessary.' Therefore we end up choosing (Woman) once or twice per week. Because it something easier. This is the tastes good, so they eat, because beautiful truth of soda.' (Man)

legumes, they don't eat anything.'

'Cookies are too good. Sometimes I don't buy them. But then my mother-in-law comes home with a package. It is hard because she knows that my son likes to eat them, and I live with her; so it gets

'da, cookies, chips, sandwiches ... Because of the children, we end up eating these things.' (Man) 
cream and candies), while adults liked the entrée and other courses of the meal. According to the authors, such behaviour contributed to make meals a stressful time and, in fact, contributed to the children's craving for sweets. On the other hand, Italian families encouraged children to express their taste for particular cheeses, sauces, pastas and vegetables, and reported enjoying sharing their meals with their children ${ }^{(38)}$. Despite children's innate preference for sweet, there is a cultural construction of taste, expressed as part of the family dynamics.

When studying Uruguayan mothers, Machín et al. found that among the reasons behind children's food choices, 'hedonics' was an important factor, as exemplified by this quote from their study: 'I buy what they like to eat because if I buy something they don't like to eat, they won't eat ${ } t^{\text {(39) }}$. In our research, the quote 'because it [soda, cookies and chips] is good, they eat, because kids like to eat it, they don't eat vegetables, they don't eat legumes, they don't eat nothing' showed that parents find it difficult dealing with their children's eating preferences. Parents thus seemed to believe that children need to eat, and as long as they eat something, they are happy.

Van Ansem et al. and Paes et al. showed that parents shaped their children's consumption of sugar-sweetened beverages $^{(40,41)}$. In our study, participants reported that their children will eat or drink those products because the father or another relative (such as a grandparent) buys them. Grandparents tend to indulge children, allowing them to eat whatever they want ${ }^{(42)}$. In Brazil, lowerincome households are more likely to have three or more generations living together, which increases the exposure of children to their grandparents' actions ${ }^{(43)}$.

Finally, children were not just consumers; they were influencers and had an impact on their own and their parents' intake of ultra-processed foods, as seen in this quote: 'soda, cookies, chips, sandwiches ... Because of the children, we end up eating these things'. This phenomenon is known as pester power ${ }^{(42)}$. Dallazen and Fiates conducted a study with parents of students (6-10 years old) from public and private institutions in Brazil and observed that the entire family ended up eating the ultraprocessed foods requested by their children - even when these foods were not part of the family food traditions ${ }^{(44)}$.

Convenience and the fact that ultra-processed foods are readily available were also important facilitators of their consumption. Convenience is one of the main characteristics of ultra-processed foods: they are convenient, do not require preparation, can be stored for a long time, and sometimes do not even require utensils (such as plates, knives, forks) to be eaten; thus, they can be consumed anywhere $^{(29,31)}$.

Some participants identified addiction as a facilitator of the consumption of ultra-processed foods. They reported to eat these foods because they were addicted to them. The term 'addiction to foods' is, however, contradictory ${ }^{(45)}$. Schulte et al. used experimental findings to support their assertion that ultra-processed foods share some pharmacokinetic properties (such as concentrated dose and rapid rate of absorption) with drugs of abuse ${ }^{(46)}$. Further understanding what individuals mean by 'addiction to food' would help explore such facilitator in more detail.

Regarding the relationship of cost and consumption of sugar-sweetened beverages, Claro et al. showed that an increase in the price of sugar-sweetened beverages would lead to a reduction in their consumption in Brazil ${ }^{(47)}$. And Duran et al. found that sugar-sweetened beverages are cheaper and more likely to be available in low-income neighbourhoods in São Paulo ${ }^{(20)}$.

The food industry designs and sells ultra-processed foods targeting some attributes that make them highly profitable ${ }^{(31)}$. These attributes matched the facilitators reported by our sample. The fact that they are hyperpalatable and addiction-like was reflected in the subcategories of taste and addiction. Their aggressive marketing might be related to children's preference. The sub-category convenience reflected their widespread availability and convenience. Their low cost of production might be mirrored in how accessible and affordable they are. All these categories interact with each other, and form a complex cycle that induces people to choose to eat ultraprocessed foods.

The present study has a few limitations. First, it was restricted to thirteen districts in the city of São Paulo and therefore does not represent the entire city. However, the sampled districts represent the socio-economic diversity found in São Paulo and cover all geographic areas of the city. Second, we did not achieve the a priori sample size defined for the qualitative arm of the ESAO-SP study, despite all our efforts. Nevertheless, a diversity of perceptions was obtained, suggesting that our sample gave us enough power to cover the matter. Finally, the study was carried out in 2012 and more recent changes and influences of the food environment on dietary intake may not have been identified. However, it is not likely that substantial changes in the food environment occurred in São Paulo city in the past 5 years. São Paulo is already served by transnational corporations seeking to expand their sales of ultra-processed products in highly populated developing countries.

Finally, participants perceived their neighbourhoods as favourable to the consumption of ultra-processed foods and reported more facilitators than barriers to their consumption. The reported barriers point to the need for the promotion of healthy eating, which should include access to nutritional information and the preservation of traditional food patterns. The reported facilitators reinforce the idea that these foods are habit-forming and that regulatory measures are necessary, particularly because children influence what adults are buying and eating. Therefore, protecting the children from aggressive marketing strategies may also protect the health of the entire family. 
To our knowledge, the present study is the first qualitative study concerning individuals' perceptions of ultraprocessed foods. Considering that eating behaviours are complex and multidimensional, qualitative studies help us understand how individuals interact with the environment for more effective public health measures to be enacted. Further qualitative studies could focus on the meanings given to ultra-processed foods by different age groups, which would contribute to the development of models to theorize the choice for ultra-processed foods.

\section{Acknowledgements}

Financial support: This work was funded by the São Paulo Research Foundation (FAPESP; grant number 2009/17517-0) and the National Council for Scientific and Technological Development (CNPq; grant numbers 559517/2010-6 and 476881/2010-2). FAPESP and CNPq had no role in study design, data collection and analysis, decision to publish or preparation of the manuscript. The content is solely the responsibility of the authors. Conflict of interest: None. Authorship: L.B.A. had responsibility for recruitment of participants, fieldwork planning, and data collection, coding and analysis. F.B.S. contributed to data analysis and interpretation and drafted the manuscript. A.C.D. had responsibility for data collection, data analysis and contributed to manuscript writing. P.C.J. conceptualized and designed the study, obtained funding for the overall research project, contributed to data analysis and interpretation and to manuscript writing. All authors read and approved the final version of the manuscript. Ethics of buman subject participation: Ethics approval was granted by the Human Research Ethics Committee of the School of Public Health of the University of São Paulo. All participants ( $n$ 48) received written information explaining the study and signed individual consent forms.

\section{References}

1. Monteiro CA, Cannon G, Moubarac J-C et al. (2015) Dietary guidelines to nourish humanity and the planet in the twenty-first century. A blueprint from Brazil. Public Health Nutr 18, 2311-2322.

2. Monteiro CA, Levy RB, Claro RM et al. (2011) Increasing consumption of ultra-processed foods and likely impact on human health: evidence from Brazil. Public Health Nutr 14, $5-13$.

3. Monteiro CA, Cannon G, Levy RB et al. (2012) The food system. Ultra-processing. The big issue for nutrition, disease, health, well-being (Commentary). World Nutr 3, 527-569.

4. Moubarac J-C, Martins APB, Claro RM et al. (2013) Consumption of ultra-processed foods and likely impact on human health. Evidence from Canada. Public Health Nutr 16, 2240-2248.

5. Juul F \& Hemmingsson E (2015) Trends in consumption of ultra-processed foods and obesity in Sweden between 1960 and 2010. Public Health Nutr 18, 3096-3107.
6. Monteiro CA, Cannon G, Levy RB et al. (2016) NOVA. The star shines bright. World Nutr 7, 28-38.

7. Louzada MLC, Martins APB, Canella DS et al. (2015) Ultraprocessed foods and the nutritional dietary profile in Brazil. Rev Saude Publica 49, 38.

8. Louzada MLC, Martins APB, Canella DS et al. (2015) Impact of ultra-processed foods on micronutrient content in the Brazilian diet. Rev Saude Publica 49, 45.

9. Steele EM, Baraldi LG, Louzada MLC et al. (2016) Ultraprocessed foods and added sugars in the US diet: evidence from a nationally representative cross-sectional study. BMJ Open 6, e009892.

10. Louzada MLC, Baraldi LG, Steele EM et al. (2015) Consumption of ultra-processed foods and obesity in Brazilian adolescents and adults. Prev Med 81, 9-15.

11. Mendonça RD, Pimenta AM, Gea A et al. (2016) Ultraprocessed foods consumption and risk of overweight/ obesity: the SUN cohort study. Am J Clin Nutr 104, 1433-1440.

12. Vandevijvere S, Monteiro C, Krebs Smith SM et al. (2013) Monitoring and benchmarking population diet quality globally: a step wise approach. Obes Rev 14, 135-149.

13. Ministry of Health of Brazil (2014) Dietary Guidelines for the Brazilian Population. Brasília: Ministério da Saúde.

14. Pan American Health Organization (2016) Nutrient Profile Model. Washington, DC: PAHO.

15. Glanz K, Rimer BK \& Viswanath K (2008) Health Behavior and Health Education: Theory, Research, and Practice. San Francisco, CA: Jossey-Bass.

16. Brunner TA, Van der Horst K \& Siegrist M (2010) Convenience food products. Drivers for consumption. Appetite 55, 498-506.

17. Botonaki A \& Mattas K (2010) Revealing the values behind convenience food consumption. Appetite $\mathbf{5 5}$, 629-638.

18. Villaça F (2011) São Paulo: urban segregation and inequality. Estud Av 25, 37-58.

19. Duran AC, Roux AVD, Maria do Rosario DO et al. (2013) Neighborhood socioeconomic characteristics and differences in the availability of healthy food stores and restaurants in Sao Paulo, Brazil. Health Place 23, 39-47.

20. Duran AC, de Almeida SL, Maria do Rosario DO et al. (2016) The role of the local retail food environment in fruit, vegetable and sugar-sweetened beverage consumption in Brazil. Public Health Nutr 19, 1093-1102.

21. Bernard HR \& Ryan GW (2010) Analyzing Qualitative Data: Systematic Approaches. Thousand Oaks, CA: SAGE Publications, Inc.

22. Monteiro CA, Moubarac JC, Cannon G et al. (2013) Ultraprocessed products are becoming dominant in the global food system. Obes Rev 14, 21-28.

23. Engler-Stringer R (2010) The domestic foodscapes of young low-income women in Montreal: cooking practices in the context of an increasingly processed food supply. Health Educ Behav 37, 211-226.

24. Lavelle F, McGowan L, Spence M et al. (2016) Barriers and facilitators to cooking from 'scratch' using basic or raw ingredients: a qualitative interview study. Appetite 107, 383-391.

25. Canella DS, Levy RB, Martins APB et al. (2014) Ultraprocessed food products and obesity in Brazilian households (2008-2009). PLoS One 9, e92752.

26. Larson N \& Story M (2009) A review of environmental influences on food choices. Ann Behav Med 38, 56-73.

27. Swinburn BA, Sacks G, Hall KD et al. (2011) The global obesity pandemic: shaped by global drivers and local environments. Lancet 378, 804-814.

28. Caspi CE, Sorensen G, Subramanian SV et al. (2012) The local food environment and diet: a systematic review. Health Place 18, 1172-1187. 
29. Monteiro CA (2010) The big issue is ultra-processing. World Nutr 1, 237-269.

30. Louzada MLC, Baraldi LG, Steele EM et al. (2015) Consumption of ultra-processed foods and obesity in Brazilian adolescents and adults. Prev Med 81, 9-15.

31. Pan American Health Organization (2015) Ultra-Processed Food and Drink Products in Latin America: Trends, Impact on Obesity, Policy Implications. Washington, DC: PAHO.

32. Sobal J, Bisogni CA, Devine CM et al. (2006) A conceptual model of the food choice process over the life course. Front Nutr Sci 3, 1.

33. Conner M \& Armitage CJ (2006) Social psychological models of food choice. Front Nutr Sci 3, 41.

34. Sato PDM, Gittelsohn J, Unsain RF et al. (2016) The use of Pierre Bourdieu's distinction concepts in scientific articles studying food and eating: a narrative review. Appetite $\mathbf{9 6}$, 174-186.

35. Sato PDM, Lourenço BH, Trude AC et al. (2016) Family meals and eating practices among mothers in Santos, Brazil: a population-based study. Appetite 103, 38-44.

36. Bourdieu P (2010) Distinction: A Social Critique of the Judgment of Taste [R Nice, translator]. London: Routledge (original work published in 1979).

37. Mallarino C, Gómez LF, González-Zapata L et al. (2013) Advertising of ultra-processed foods and beverages: children as a vulnerable population. Rev Saude Publica 47, 1006-1010.

38. Ochs E, Pontecorvo C \& Fasulo A (1996) Socializing taste. Ethnos 61, 7-46.
39. Machín L, Giménez A, Curutchet MR et al. (2016) Motives underlying food choice for children and perception of nutritional information among low-income mothers in a Latin American country. J Nutr Educ Behav 48, 478-485.

40. Van Ansem WJ, Schrijvers CT, Rodenburg G et al. (2014) Maternal educational level and children's healthy eating behaviour: role of the home food environment (crosssectional results from the INPACT study). Int J Behav Nutr Phys Act 11, 1.

41. Paes VM, Hesketh K, O'Malley C et al. (2015) Determinants of sugar-sweetened beverage consumption in young children: a systematic review. Obes Rev 16, 903-913.

42. Roberts EM (2006) Negotiating food choice: parents' perception of children's eating behaviour. Anthropol Noteb 12, 63-77.

43. Scagliusi FB, da Rocha Pereira P, Unsain RF et al. (2016) Eating at the table, on the couch and in bed: an exploration of different locus of commensality in the discourses of Brazilian working mothers. Appetite 103, 80-86.

44. Dallazen C \& Medeiros Rataichesck Fiates G (2014) Brazilian parents' perceptions of children's influence on family food purchases. Br Food J 116, 2016-2025.

45. Ziauddeen H \& Fletcher PC (2013) Is food addiction a valid and useful concept? Obes Rev 14, 19-28.

46. Schulte EM, Avena NM \& Gearhardt AN (2015) Which foods may be addictive? The roles of processing, fat content, and glycemic load. PLoS One 10, e0117959.

47. Claro RM, Levy RB, Popkin BM et al. (2012) Sugar-sweetened beverage taxes in Brazil. Am J Public Health 102, 178-183. 